\title{
The Impact of Workplace Motivation on Employee Performance within the Ministry of Health in Swaziland
}

\author{
Article by Patrick Masitsela Mhlanga, \\ Ph.D in Management, Texila American University, Swaziland \\ E-mail: mhlangamasitsela@texilaconnect.com
}

\begin{abstract}
The study investigates the Impact of Workplace Motivation on Employee Performance within the Ministry of Health in Swaziland. Seventy seven (77) respondents selected from the four geographical regions of the country which are Manzini, Lubombo, Shiselweni and Hhohho.

Findings from the study showed that extrinsic motivation given to health care workers has a significant influence on worker performance and that a relationship exist between employee motivation and the organizational performance. In terms of factors influencing motivation at the Ministry of Health, the study revealed that there are factors which influence motivation in the workplace. The factors identified are such as leadership, appreciation and recognition, reward system, goal setting, structure of work and organizational culture.

When assessing the impact of the motivational factors on employee performance at the Ministry of Health, Swaziland to support other findings the results from the analysis showed that factors such as leadership, empowerment and recognition have positive effect on employee motivation.

As a major recommendation, the Ministry of Health should establish and define an "essential employee motivation package" with clearly defined policies and procedures to motivate, attract, retain and satisfy its employees. Again for effective leadership and supervisor/employee relationship, the Ministry should establish leadership and management (change management) in-service training programmes for supervisors and senior management. The findings of this study can be used to provide some solutions to motivate employees.
\end{abstract}

Keywords: Motivation, Employee Performance, Leadership, Empowerment and Recognition, and Remuneration.

\section{Introduction}

In Swaziland, employees in the ministry of health form part of the equation as assets and contribute enormously to development of a nation. The role played by health workforce is crucial and this then supports the fact that there is no business without the workforce. However, Ministry of Health is facing a number of challenges. Members of the public have raised numerous complaints about the declining standard of care and low morale amongst Ministry of Health employees. This then prompted the researcher's curiosity on workplace motivation.

Motivation comes in many forms at work. One may feel motivated because something or reward has been given to him or her and another may feel self -motivated to do something without being given anything. However, work-place managers are eager to see the goal of the organization set being accomplished as well as targets for profit. So for managers it becomes a worry when set goals are not achieved when the organization has employed staff. It is very essential for an organization to succeed in the competitive environment and meet targets.

The aim of the study was to assess the Impact of Workplace Motivation on Employee Performance within the Ministry of Health in Swaziland. Specifically the study was to address the following objectives; 
Texila International Journal of Management

Volume 2, Issue 2, Dec 2016

- To determine the factors influencing employee motivation at the Ministry of Health, Swaziland

- To evaluate the impact of the motivational factors on employee performance at the Ministry of Health, Swaziland; and

- To make recommendations regarding motivational approaches that can be used as best practices and robust corporate governance.

In terms of factors influencing motivation at the Ministry of Health, the study revealed that there are factors which influence motivation in the workplace. The factors identified are such as leadership, appreciation and recognition, reward system, goal setting, structure of work and organizational culture. While this shows existing solutions within the workplace, the study has showed that factors of workplace leadership, empowerment and recognition have positive effect on employee motivation. However, there were some limitations of this study as the results cannot be generalised over the entire population because of the small sample size but the results can be used to develop some strategies to solve workplace motivation issues.

\section{Methods}

The study has been undertaken through a descriptive design seeking to describe the current status of employee motivation in the workplace in order to provide systemic information about the phenomenon. The research design did not begin with a hypothesis but after data collection during the pilot phase a hypothesis was then developed. The analysis and synthesis of data collected enabled the researcher to test the hypothesis. A systematic collection of data through organized units and departments within the ministry of health was done.

The study followed some processes including first of all making my own observation in the ministry of health about whether employees were motivated or not and what influences motivation. This was followed by investigation of theory surrounding employee motivation and then hypothesizing about employee motivation with possible outcome predictions and findings. The process was then followed by formulation of research questionnaire, a structured tool for data collection. Data collection exercise was undertaken after clearance from the Swaziland Research and Scientific Review Board. Data verification and analysis was done.

These included a descriptive/correlational research methodology, as well as causalcomparative research methodology. This was to establish cause-effect relationships among the two variables -the factors influencing employee motivation and the impact on performance.

A multi-disciplinary survey through a selected population sampled from the Ministry of Health was conducted and included disciplines such as professionals, support staff, and administrators within the Ministry. As would be further elaborated in the next segment, multifaceted approaches were used for this study. This study targeted professionals and nonprofessionals working in various departments and units of the Ministry of Health, in Swaziland. However, because of the nature of their professional diversity, and given the fact that the ministry has an overall employment of over 3000 people, it became imperative to sample a section of these. Therefore, a sample size of 100 employees, of a diverse mix, were selected and targeted. Each population element was given a questionnaire, and asked to fill and return it within 72 hours.

A simple random sample (SRS) of size $n$ consists of $n$ individuals from the population chosen in such a way that every set of $n$ individuals has an equal chance to be the sample actually selected (Moore and McCabe: 2006). Mancosa (2008) describes cluster sampling as dividing the population into internally heterogeneous subgroups amongst a homogeneous population. In this case, population elements become the subgroups or clusters, as opposed to individuals. When individuals in the population are not given equal chances of being selected is called non-probability sampling.

Having carefully examined each of the above approaches, the researcher chose to use probability sampling, since it uses conventionally unbiased approaches that are usually fairly 
representative of the entire population. Two methods were used; stratification and simple random sampling. In stratifying the population, three distinct strata were identified. These were 1) professionals, 2) support staff, and 3) senior administrators (who may as well represent the employer).

Researchers should use precise terminology in phasing the questions to avoid vagueness or misinterpretation or ambiguity when developing a research instrument. Research questionnaires should first be pretested through a miniature/pilot survey (Leary 1995).

In this study, the researcher decided to use a questionnaire as the preferred research instrument. A research questionnaire was developed with four sections and all comprising of closed -ended questions which were similarly designed for direct responses. This type of questions were used to obtain specific pieces of information. The nature of the tool limited choices for the respondents.

30 simple questions were asked, under four distinct categories. These categories were 1) demographics, 2) Job Satisfaction 3) Supervisor relations and job performance, and 4) Work environment, pay and benefits. So both extrinsic and intrinsic elements were considered. On the questionnaire, these were termed 'sections'. Section 1 had five questions, Section 2 had eight questions, seven questions for Section 3, and 10 questions for Section 4.

The questions in sections 2 to 4 , were all aligned to the objectives of the study mentioned in Chapter 1. Section 1 questions, demographics, asked for the respondent's age, sex, position/grade in the ministry, level of education reached, and number of years in service.

In determining job satisfaction, thus Section 2, the population elements were asked how satisfied they were with their positions at the ministry, whether they enjoyed working every day and performing at their best, how motivated they were intrinsically, and whether they got any kind of extrinsic motivation from the department, among other questions.

Section 3, sought to interrogate supervisor relations and job performance, by asking such questions as how respondents rate the management style of their supervisors, and establishing if there is constant and two-way communication between supervisors and employees at their respective departments. The two-way communication is representative of Management by Participation, as well as MBO (Management by Objectives.)

The last section, which focussed on work environment, pay and benefits, had questions that probed how satisfied employees were about the safety, health and comfort of their work environment. They were asked if they were satisfied with their salaries and health benefits, and what they felt on motivation's relationship to general work performance.

The questionnaires were hand-delivered to all respondents, and the researcher was available to explain those questions that they needed clarified.

For professionals and administrators, they filled in the questionnaires themselves, while face to face interviews were administered for support staff, with answers recorded on the questionnaire. This was done in order to ensure clarity of the questions and also correct capturing of the answers.

Administering questionnaires through interviews has several advantages. These include clarification on complex questions, probing and verification, and spontaneity of participants. Also, sequence of questions can be altered. It is guaranteed that it will be delivered, and gives better quality and depth of data (uk.sagepub.com).

Meanwhile, the questionnaires were collected on the same day of delivery, as answering had been made simple and speedy through the circling method. On average, respondents took 20 minutes to fill in the questionnaires, hence it became logical that these get collected same day.

Data analysis started with organization of data and categorization of data in search of patterns, themes, and meanings. The data presented in the next chapter was analyzed from mainly descriptive statistics, although inferential statistics were also used. Data was collected from the answered questionnaires which had definite answers given as options. In collation, a tally system was used in counting the number of respondents per each question. The tally was then interpreted numerically through filling in a result tables. The table was then entered into 
Texila International Journal of Management

Volume 2, Issue 2, Dec 2016

Microsoft Excel Spreadsheet to create illustrative and presentation tools. The tools are bar graphs, and pie charts. These were mainly chosen for comparative purposes, and for ease of interpretation. Also where there were more than two possible options, the graphs aided determining the modal choices. In the study more than one responses in any given question were regarded as invalid response.

The statistical method used in the study is correlation (r) so as to show the relationships of the two variables. The Pearson correlation technique has been used and the main result of a correlation called correlation coefficient ranges from -1.0 to +1.0 . The closer $r$ is to +1 or -1 , then more closely the two variables are related.

\section{Results}

The population sample consisted of 77 respondents. 5.2 percent of these were aged between 18 and 25 years, 19.5 percent were aged between 26 and 30 years, 41.6 percent between 31 and 40 years, 19.5 percent were between 41 and 50 years, while 14.3 percent were between 51 and 60 years. The modal age group in the Ministry of Health is 30 to 40 years, while there is a significant employee population in the age group 26 to 30 years. This indicates possible sustainability in employee turnover for the ministry since the age of retirement is 60 years. In terms of job satisfaction about 42.9 percent of the population sample was fairly satisfied (thus neither satisfied nor dissatisfied), 24.7 percent are satisfied, 14.3 percent dissatisfied, and an equal number (7.8 percent) are both highly satisfied and highly dissatisfied. 2.6 percent opted not to reveal their satisfaction levels.

In terms of whether Ministry of Health employees enjoy going to work and performing at their best 66.2 percent of the Ministry of Health employees like going to work and performing at their best. 29.9 percent do not like going to work, while 3.9 percent would rather not comment. About two thirds of employees enjoy going to work and performing at their best.

Only 11.7 percent of the population sample said they were not motivated to assist their departments meet objectives, whilst 36.4 percent reported that they were slightly motivated. 48.1 percent said they were motivated, and 3.9 percent did not answer. Although below 50 percent, a majority of employees in the Ministry of Health are motivated to assist their departments meet objectives, while a lot more are slightly motivated.

Only 26 percent of the respondents prefer to stay at their current jobs because of the challenging job assignments. 39 percent of the population sample, representing the majority, mentioned salary/benefits stability/security as their reason for staying at their current job. 9.1 percent mentioned interesting working hours as their reason for staying at their current job. 7.8 percent of the population sample stayed for good vacation leave. 13 percent opted for convenient retirement benefits as a reason for staying. 16.9 percent said clear work assignments was the reason they stayed at their current job. 10.4 percent mentioned training opportunities as a reason. 22.1 percent mentioned supportive supervision as a reason for staying at their current job. 11.7 percent said they stayed for other reasons

37.7 percent of the population sample felt they were not empowered by their supervisors to pursue opportunities for professional development. 29.9 percent of the population sample said they were sometimes empowered to pursue these opportunities, while another 29.9 percent of the population sample said they were empowered by the supervisors to pursue professional development opportunities. About 74 percent of the respondents said they had not contemplated transfers from the ministry in the last twelve months. 23.4 percent reported they had contemplated such, while 2.6 percent did not respond to this part of the questionnaire. Whilst 74 percent of the Ministry of Health employees have not contemplated transfers from the ministry, a significant number have contemplated transferring.

About64.9 percent of the respondents said they felt there were no efforts made by the ministry to motivate staff. 33.8 percent said there were some efforts being made. However, 1.3 percent did not answer. Nearly two-thirds of the respondents felt there were no efforts that there were made to motivate them. However, a third feel there are some efforts made to motivate staff. In terms of whether employees are applauded by their supervisors for a job 
well done or not as shown in the figure 3.1.1, about 24.7 percent of the respondents said their supervisors neither applauded them nor encourage them after a job well done. 48.1 percent said they were sometimes applauded by their supervisor for a job done well. One respondent opted to add that ' ... supervisors always looked for mistakes'. Meanwhile, 27.3 percent said they were applauded by their supervisors.

Only 15.6 percent of the respondents said their supervisors were not communicating performance expectations clearly. 46.8 percent said supervisors were sometimes clearly communicating performance expectations. 37.7 percent said supervisors communicated performance expectations clearly. Respondents were asked about the workplace environment and only 1.3 percent of the respondents said they were highly satisfied with safety, health, and comfort of the work environment. 16.9 percent of the respondents said they were satisfied. 37.7 percent of the respondents said they were fairly satisfied. 24.7 percent said they were dissatisfied. 19.5 percent reported that they were highly dissatisfied. More than 40 percent feel dissatisfied about health, comfort, and safety.

71.4 percent of the respondents said they did not have necessary tools, adequate working space, and appropriate equipment to perform their duties efficiently. 27.3 percent of the respondents said they did. 1.3 percent opted not to answer. A majority of employees in the Ministry of Health feel they do not have necessary tools, adequate working space, and equipment.19.5 percent said motivational incentives did not encourage efficiency in reaching the goals of the ministry. 46.8 percent said yes, motivational incentives encourage efficiency in achieving the ministry's goals and objectives. 2.6 percent said there were no incentives. 31.2 percent did not respond to the question.

About 13 percent of the respondents reported that lack of motivation did not generate poor performance. 53.2 percent said yes, lack of incentives and motivation generates poor performance. 33.8 percent did not answer this sub-section. In terms of contribution of lack of motivation to employee absenteeism and turnover about 61 percent of the respondents expressed that lack of motivation contributed to employee absenteeism and turnover. Only6.5 percent said no, they did not believe lack of motivation contributes to employee absenteeism and turnover, whilst 32.5 percent opted not to respond to the question.

Only 2.6 percent of the respondents indicated that motivation and productivity are not related to creating an environment that maximises the factors that affect performance. 20.8 percent said they were unsure whether employee motivation and productivity could be improved by creating an environment that maximised the factors that affected performance. 76.6 percent of the respondents said yes, motivation and productivity could be enhanced by creating an environment that maximised factors that affect performance.

The factors of employee motivation within the ministry of health were ranked according to scale and leadership was ranked as the leading factor as most respondents felt that for them to be motivated in the workplace leadership of the managers can influence positively or negatively. For-instance if top managers have good leadership skills then employees may feel motivated to perform tasks assigned to them. When leaders of an organization pay special attention to the needs of the people then that leads to committed employees performing to their very best in the workplace.

\section{Discussions}

Findings from the literature has shown that answers are related to needs, motivators, hygiene factors, goal setting, rewards and expectations. There is still a growing debate on the causal relationships and linkages between motivation and performance in the workplace. Hornby and Sidney (1988) states that performance in the workplace rely on worker's level of motivation which enables the worker to perform at his best ability. Whereas Kanfer (1999) argues that it depends on the workers control when it comes to motivation and performance.

SHRM-HR (2010) states that employee motivation within the workplace is influenced by factors such as employee engagement, organizational vision, and values, management acknowledgement and appreciation of work well done, and overall authenticity of leadership. 
Texila International Journal of Management

Volume 2, Issue 2, Dec 2016

In the Harvard Business Review article Heidi (2014) states that people are wired to connect to social networks and therefore people want to work together.

In terms of factors influencing motivation at the Ministry of Health, my findings revealed that there are factors which influence motivation in the workplace. The factors were ranked in the order of importance listed below;

1. Leadership style

2. Appreciation and recognition

3. Reward system

4. Goal setting

5. Structure of work

6. Organizational climate

Leadership style became the most important factor that influences work performance, according to the employees of the ministry. The influence of making people perform the task set because people have put trust in you is essential and indeed sets the tone of leadership style. The findings of the study corroborated with Maurer (2001) supporting the fact there are factors that influence employee job satisfaction at work and is associated with organizational achievement (June et al, 2006). When assessing the impact of the motivational factors on employee performance at the Ministry of Health, Swaziland to support other findings the results from the analysis showed that factors such as leadership, empowerment and recognition have positive effect on employee motivation. The results of the study showed that a relationship exist between employee motivation and the organizational performance.

However, there results of the study on the other hand have shown that there is great dissatisfaction with regards to poor salaries in the ministry of health. Actually, an overwhelming number of employees of the ministry outright revealed that they felt they were underpaid for their work. This poses a great threat to the ministry's functionality, as salaries are the most basic form of motivation.

\section{Conclusions}

The results of the study showed that extrinsic motivation given to health care workers has a significant influence on worker performance and that a relationship exist between employee motivation and the organizational performance. As a major recommendation, the Ministry of Health establish and define an "essential employee motivation package" with clearly defined policies and procedures to motivate, attract, retain and satisfy its employees. Again for effective leadership and supervisor/employee relationship, the Ministry should establish leadership and management (change management) in-service training programmes for supervisors and senior management.

Other recommendations includes; improvements in workplace relationships between the supervisor and the employee in as far as appreciating the work well done by the employee as well as inclusion of employees in nominations for award for positive re-enforcement. Serious Improvements in on workplace environments and this means that organizations should focus entirely on establishing positive practice environments which acts as hygiene factors of motivation. A major study to look further at the relationship between the factors and performance qualitatively is recommended to examine closely the relationships. The in-depth study can also be extended to cover the entire civil service.

Staff motivation remains an issue to be investigated thoroughly and even looking at the entire public service. One cannot draw conclusions to recommend strategies for the entire public sector or generalize the results to include all public sector employees but this study has generated some new information especially the fact that leadership style plays a very crucial role in enhancing employee motivation and performance even though employee empowerment and recognition also plays a critical role. 
Figures and tables

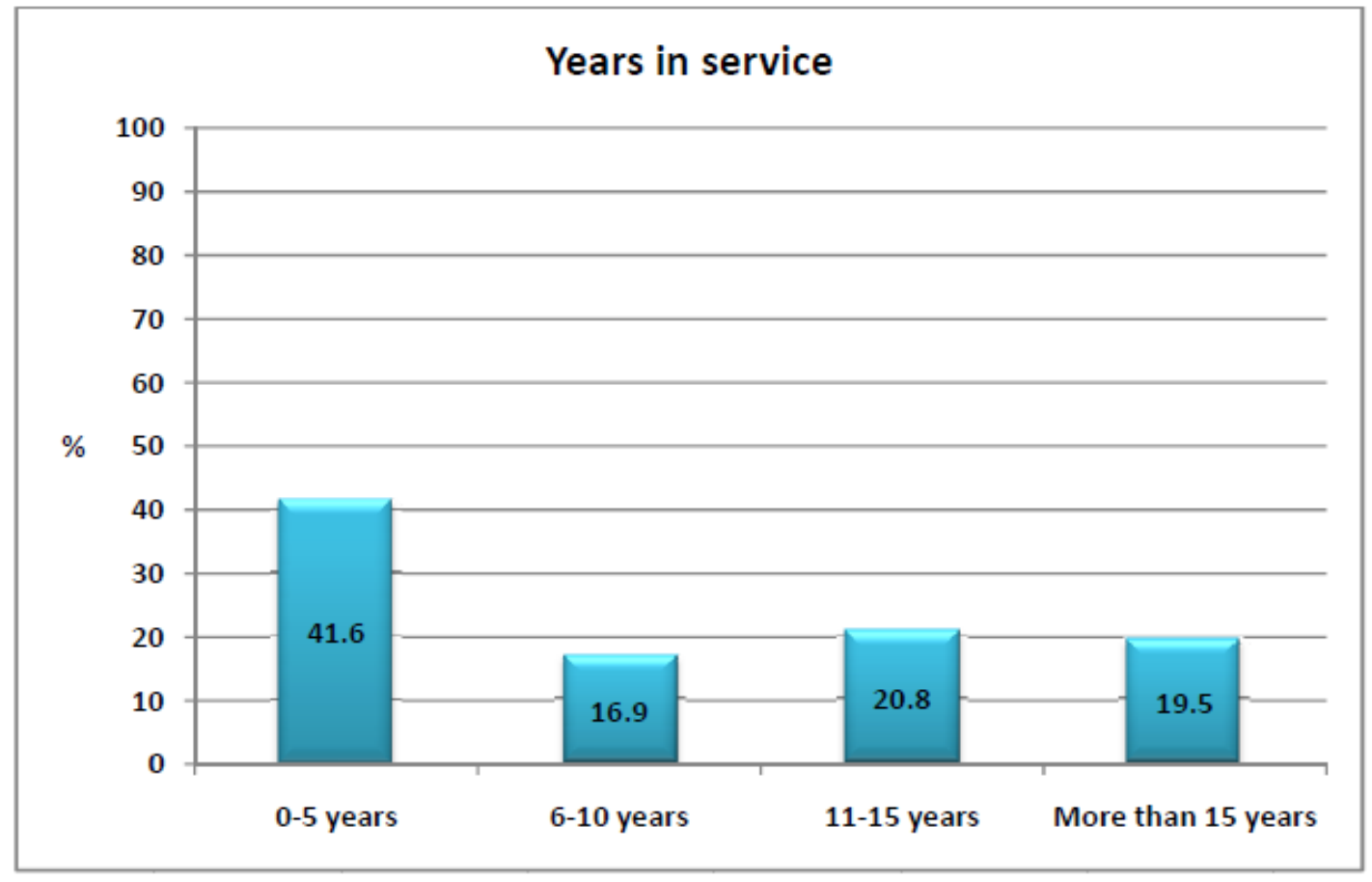

Figure 1.1. The table below shows the years in service of the population sample.

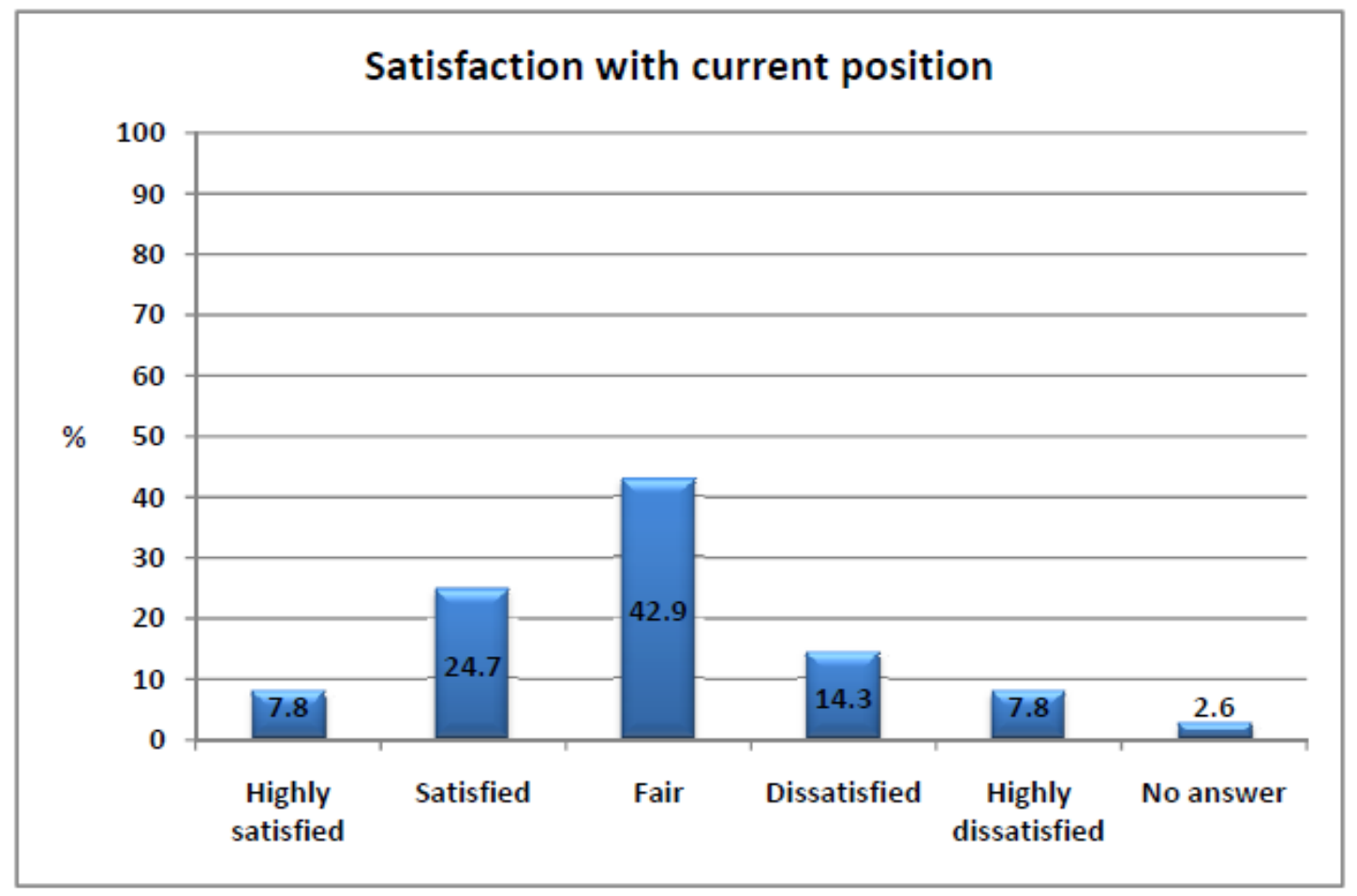

Figure 1.2. The table below shows the levels of job satisfaction with current position 
Texila International Journal of Management

Volume 2, Issue 2, Dec 2016

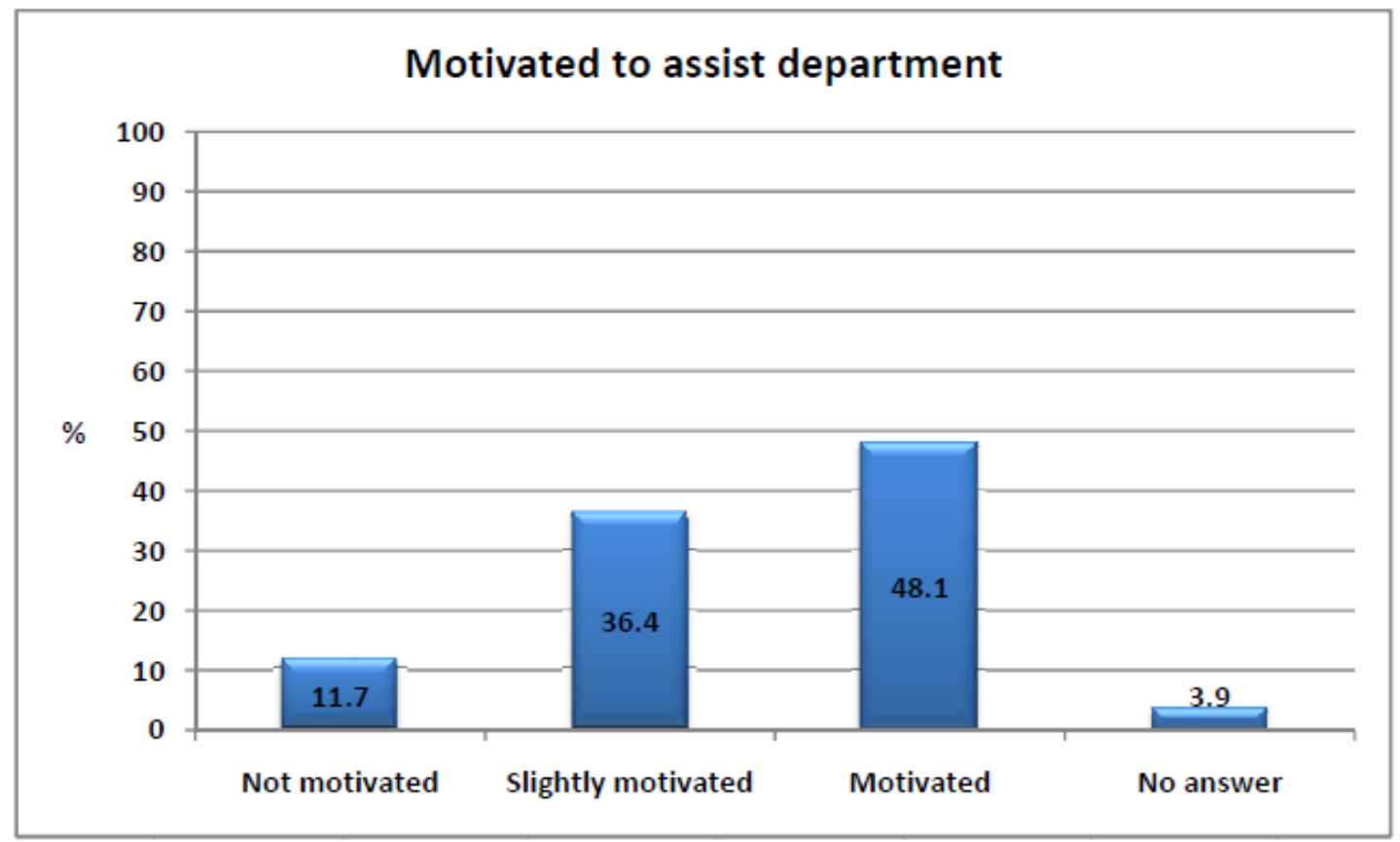

Figure 1.3. The table below shows the level of motivation in assisting departments meet their objectives.

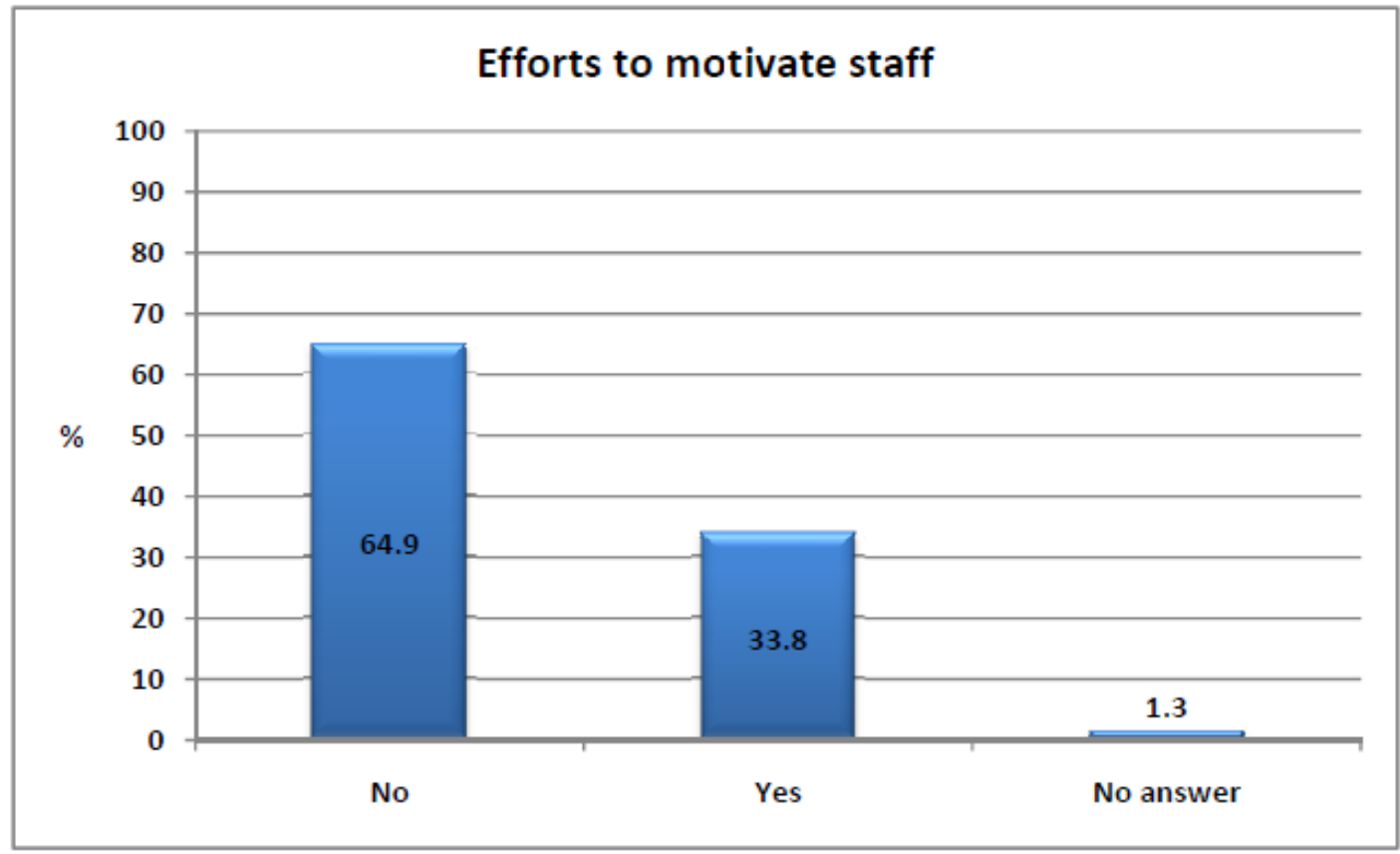

Figure 1.4. The table below shows employees' observations on efforts made by departments to motivate staff. 


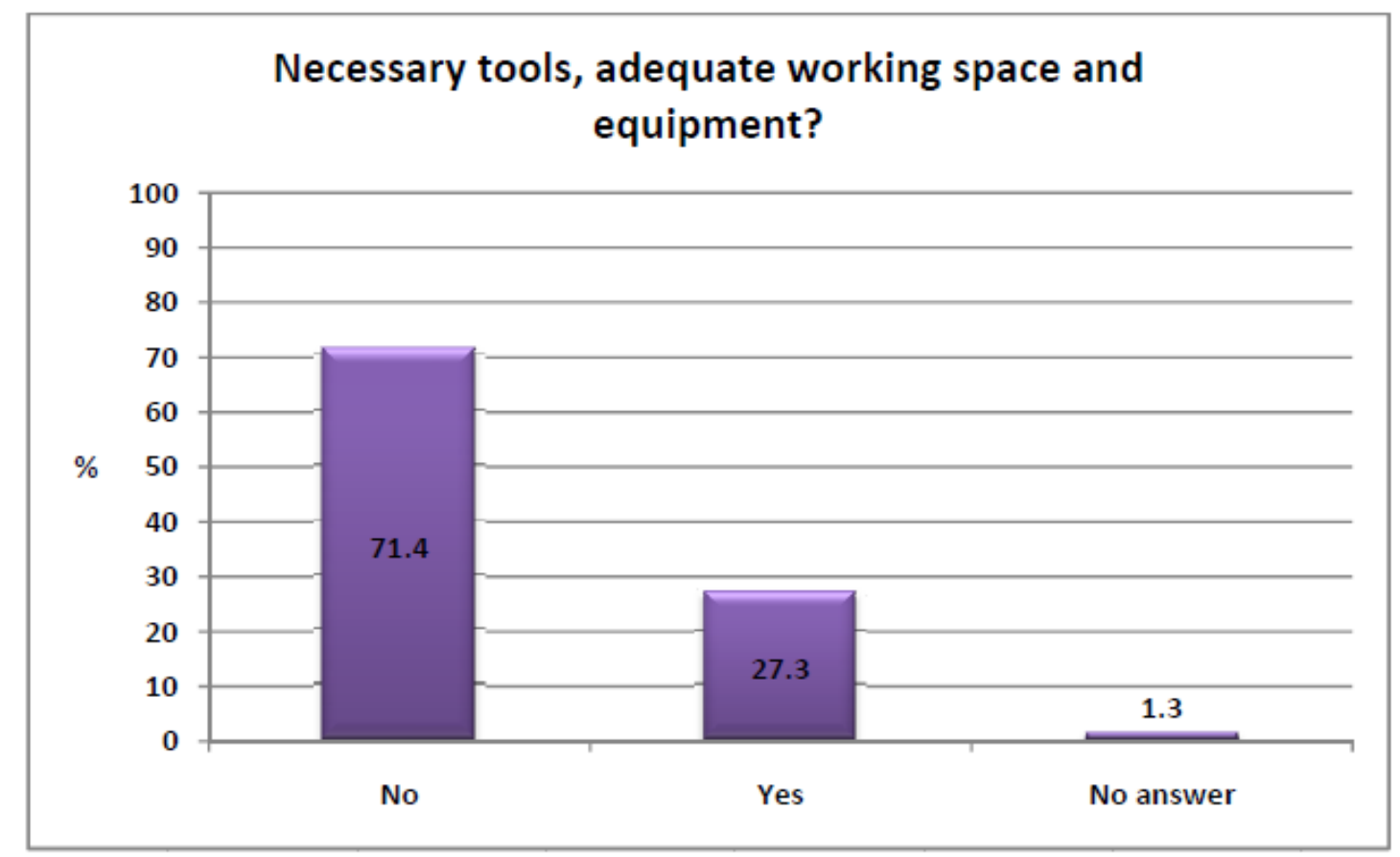

Figure 1.5. The table below shows whether employees feel they have the necessary tools, adequate working space, and appropriate equipment for performing their duties efficiently

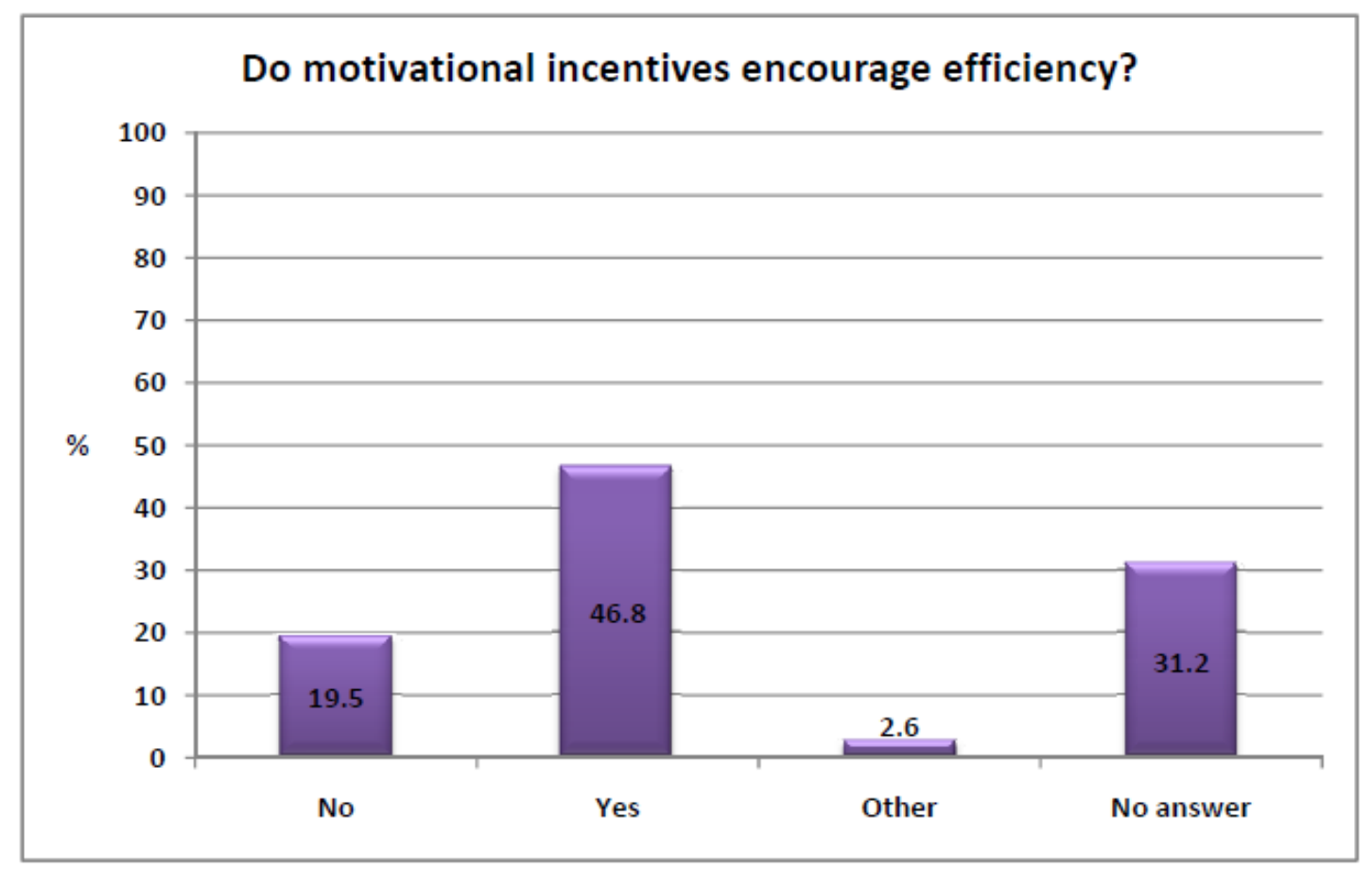

Figure 1.6. The table below shows whether motivational incentives encourage efficiency in achieving the ministry's goals and objectives. 
Texila International Journal of Management

Volume 2, Issue 2, Dec 2016

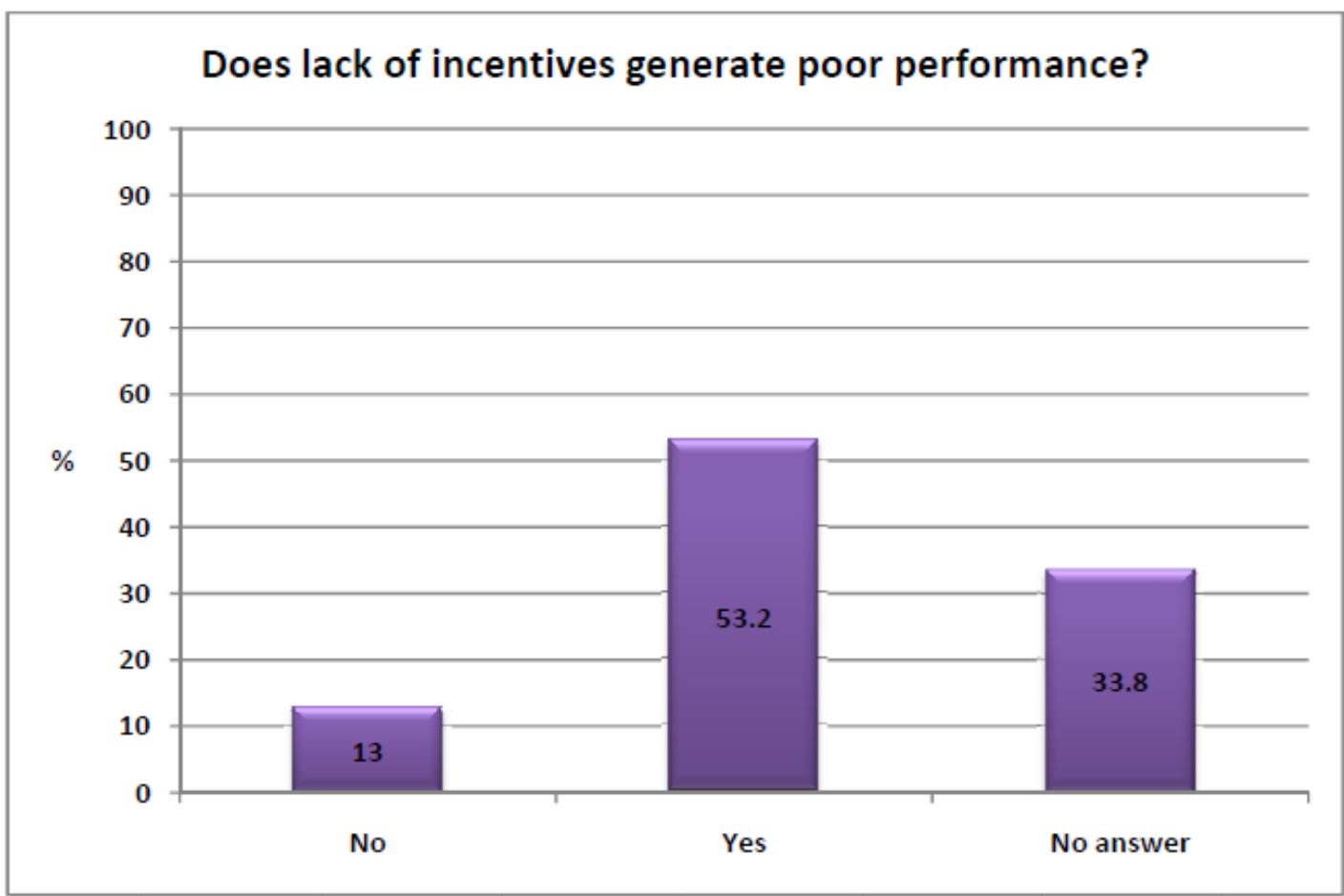

Figure 1.7. The table below shows whether lack of incentives/motivation generate poor performance.

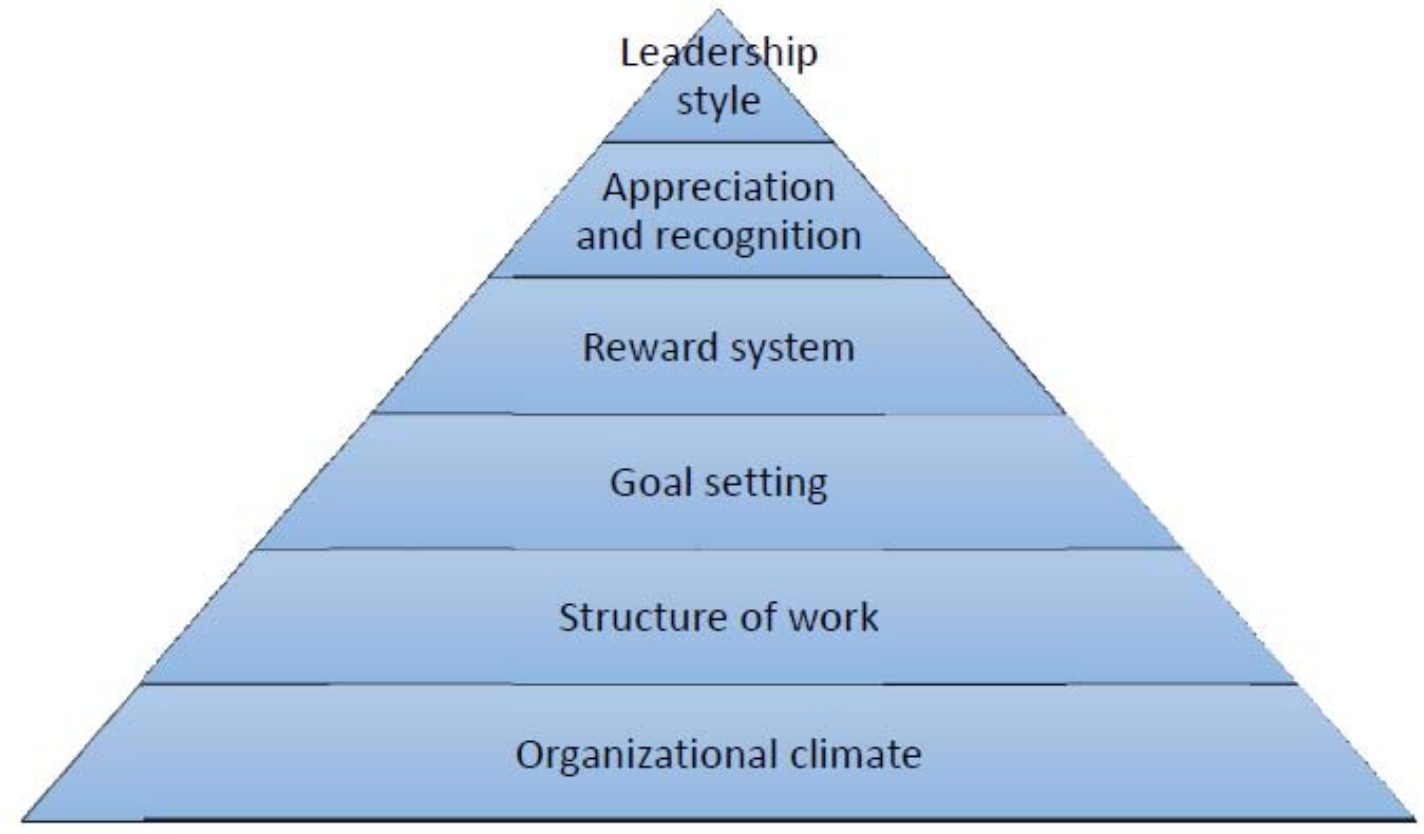

Figure 1.8. The diagram below shows how respondents ranked factors influencing motivation and performance in the workplace in order of importance. 


\section{References}

[1]. Cohen, L., Manion, L., Morrisoon, K. (2000). Research methods in education. 5th edition. London: RoutledgeFalmer.

[2]. Collins English Dictionary. (1991). Third edition. Glasgow: HarperCollins

[3]. Educational-business.com (2011) Adapted from Herzberg's Motivational Theory: Principles of OrganisationalBehaviour. Fincham and Rhodes. 2012.

[4]. Envision software (2013).

[5]. Ghuhen, R.M. (2009). Knowledge, and practices regarding tuberculosis among gold miners. In Tanzania. (Masters Dissertation). Available from the University of South Africa.

[6]. Heidi. G. H. (2014). Managers can motivate employees with one word. Harvard Business Review.

[7]. SHRM-HR. (2010). Glossary: www. Shrm.org/template tools

[8]. MacKay, A. (2007) "Motivation Ability and Confidence Building in People” Taylor \& Francis

[9]. Mathcs.duq.edu (2011).

[10]. McMillan, J.H., Schumacher, S. (2001). Research in education: a conceptual introduction. $5^{\text {th }}$ edition. New York: Addison, Wesley Longman. 